\title{
Otimização da reação de polimerase em cadeia para detecção de Toxoplasma gondii em sangue venoso e placenta de gestantes
}

\author{
Optimization of Toxoplasma gondii detection by PCR in pregnants blood and placenta
}

\author{
Silvia Maria Spalding ${ }^{1}$ \\ Maria Regina Reis Amendoeira ${ }^{2}$ \\ Janice M.C. Coelho ${ }^{3}$ \\ Sergio O. Angel ${ }^{4}$
}

\begin{tabular}{|c|c|}
\hline unitermos & resumo \\
\hline $\begin{array}{l}\text { PCR } \\
\text { Toxoplasma gondii }\end{array}$ & $\begin{array}{l}\text { A detecção de Toxoplasma gondii no sangue venoso e na placenta de gestantes pela reação } \\
\text { de polimerase em cadeia pode facilitar o diagnóstico pré-natal da toxoplasmose congênita. } \\
\text { Foram avaliadas gestantes IgM-reagentes e os seus filhos. Além das dosagens de IgG, IgM, } \\
\text { IgA e reação de avidez de IgG (MEIA), foram realizadas a técnica de imunoperoxidase e a } \\
\text { inoculação em camundongos. De cada amostra foi efetuada amplificação gênica com primers } \\
\text { do gene B1 e novos primers do gene TGR (chamados ABGTg7 C1 e N1). É preciso observar } \\
\text { que o tratamento poderia ser responsável por uma diminuição da infecção. Desta forma, o } \\
\text { diagnóstico negativo confirmaria a eficiência do tratamento preventivo na replicação } \\
\text { parasitária no útero. A reação de polimerase em cadeia mostrou-se sensível e específica; } \\
\text { evidenciou a presença de um a dez taquizoítas; pode ser utilizada com segurança e } \\
\text { confiabilidade, além de tornar rápido o diagnóstico da toxoplasmose congênita, sendo, } \\
\text { assim, ferramenta importante na avaliação pré-natal. }\end{array}$ \\
\hline
\end{tabular}


maior sensibilidade (92\%-97,4\%) e especificidade (100\%) do que os outros métodos de diagnóstico já citados $(6,11$, 14). Com a introdução de diagnóstico sensível e precoce para a avaliação de gestantes, é possível iniciar terapêutica específica que previne a transmissão desta protozoose ou minimiza o desenvolvimento de lesões no feto.

O objetivo deste trabalho foi o estabelecimento de um diagnóstico de PCR in house, através de diferentes primers, avaliando a sensibilidade e a especificidade em material de sangue total e placenta.

\section{Material e métodos}

\section{Pacientes e controles}

Foram estabelecidos dois grupos. O primeiro grupo, o controle, era constituído por 31 mulheres soronegativas (IgG e IgM não-reagentes) durante toda a gestação e pelos 31 recém-nascidos respectivos. Foram efetuadas dosagens de IgC (Elisa), de IgG (IFI) e de IgA (MEIA). Nesta mesma data, foi coletado sangue com EDTA para tentar evidenciar o parasito por inoculação em camundongos e PCR. No momento do parto, coletaram-se as placentas de cinco mulheres para realizar a técnica de imunoperoxidase, a inoculação em camundongos e a PCR.

No primeiro contato com as crianças, após o parto, foi coletado sangue com EDTA para a inoculação em animais e PCR e sangue sem EDTA para a realização de dosagens sorológicas através das mesmas metodologias já referidas.

O outro grupo era formado por 50 gestantes soropositivas (IgG e IgM positivas) e seus 51 recém-nascidos (um parto gemelar). No momento do parto, coletaramse as placentas de 18 mulheres para realizar a técnica de imunoperoxidase, a inoculação em camundongos e a PCR. Efetuaram-se também as mesmas metodologias em quatro cordões umbilicais. Neste grupo, além dos métodos de diagnóstico já citados no grupo-controle, foi realizada a reação de avidez de $\lg G$ (MEIA).

Todas as mães e seus filhos foram acompanhados clínica e sorologicamente até, no mínimo, o final do primeiro ano de vida da criança.

\section{Metodologia}

A metodologia de extração do DNA do T. gondii foi realizada conforme Angel et al. (1), e a de amplificação gênica, conforme Ho-Yen et al. (15), com modificações.

\section{Teste de sensibilidade}

A suspensão de taquizoítas de T. gondii foi retirada do líquido peritoneal de camundongos previamente infectados, e foram preparados tubos com as concentrações que variaram de 1 a $10^{7}$ taquizoítas. Foram efetuados os procedimentos de extração e quantificação do DNA. Para a execução da reação de amplificação foram utilizados 100ng.

\section{Teste de especificidade}

Para o teste de especificidade foram amplificadas amostras de DNA: humano, Trypanosoma cruzi, Leishmania amazonensis, Trichuris trichiura, Cryptosporidium spp. Plasmodium falciparum, Echinococus granulosus, Mycobacterium tuberculosis e Neisseria meningitidis.

\section{Oligonucleotídeos}

Foram utilizados dois pares de primers do gene B1 correspondentes aos nucleotídeos 694-714, 887-868, 757 776 e 853-831. Para a realização da PCR simples, os primers Toxo-N1 (5'- GGAACTGCATCCGTTCATGAG - 3') e ToxoC1 (5' - TCTTTAAAGCGTTCGTGGTC - 3'). Para a realização da PCR nested fez-se uso dos primers Toxo-N2 $\left(5^{\prime}\right.$ - TGCATAGGTTGCAGTCACTG - 3') e Toxo-C2 (5' - GGCGACCAATCTGCGAATACACC - 3').

Também foi utilizada a seqüência do elemento repetitivo em tandem TGR (4) através do par de primers ABGTg C1 (5' - TCTTTAAAGCGTTCGTGGTC-3') e N1 (5' - GGAACTGCATCCGTTCATGAG-3') em amplificação simples. Estes primers foram desenhados a partir do alinhamento de seqüências obtidas dos elementos TGR 1E, 1 A, 2 e 4 (Cristina et al., 1991) e dos elementos ABGTg7 e ABGTg8 (18).

\section{Processamento das amostras}

Foram colocados $500 \mu \mathrm{l}$ da amostra de sangue total e, para as amostras de placenta, cortados fragmentos (de $1 \mathrm{~cm}^{3}$ ) de, aproximadamente, $200 \mathrm{~g}$ de placenta, os quais foram triturados em gral com TE. A mistura obtida foi filtrada e foram realizadas três lavagens com TE (Tris- $\mathrm{HCl}$ [10mM], EDTA [1 $\mathrm{mM}], \mathrm{pH} 8)$. O sedimento foi ressuspenso em $300 \mu \mathrm{l}$ de TE, sendo-lhe adicionados $5 \mu \mathrm{l}$ de proteinase $\mathrm{K} 20 \mathrm{mg} / \mathrm{ml}$. Após, o material foi incubado a $56^{\circ} \mathrm{C}$ durante duas horas. Depois desta incubação, foi iniciada a extração do DNA pela adição de $300 \mu \mathrm{l}$ de fenol tamponado. A fase aquosa foi retirada e adicionaram-se $300 \mu$ l de fenol: clorofórmio/álcool isoamílico $(1: 1)$ e, após, com $300 \mu$ lde clorofórmio/álcool isoamílico. Foi adicionado etanol a 
100\%. Em paralelo, foi realizado o controle da extração de DNA. A quantificação do DNA foi realizada em gel de agarose a $1 \%$.

\section{Deteç̧ão da PCR}

Foi preparada a mistura de reação nas seguintes concentrações: tampão $10 \mu \mathrm{l} \times 5 \mu \mathrm{l} ; \mathrm{MgCl}(50 \mathrm{mM}) 1,5 \mu l$; primer Toxo-N1 (50pmol/ $\mu \mathrm{l}) 1 \mu \mathrm{l}$; primer Toxo-C1 (50pmol/ $\mu \mathrm{l}) 1 \mu \mathrm{l}$; DNTPs $(10 \mathrm{mM}) 1 \mu \mathrm{l}$; Taq polimerase $0,5 \mu \mathrm{l}$; água Mili-Q q.s.p. $50 \mu \mathrm{l}$; óleo mineral $30 \mu \mathrm{l}$. Foram acrescentados em cada bateria de testes três controles positivos, um controle negativo de extração e um de reação.

Foi utilizada a seguinte programação $95^{\circ} \mathrm{C}$ por $4 \mathrm{~min}$ para desnaturação, 35 ciclos: numa temperatura de $95^{\circ} \mathrm{C}$ durante $1 \mathrm{~min}$ para desnaturação, $55^{\circ} \mathrm{C}$ por $45 \mathrm{~s}$ para anelamento, $72^{\circ} \mathrm{C}$ por $1 \mathrm{~min}$ para extensão e, finalizando, uma incubação adicional a $72^{\circ} \mathrm{C}$ durante $10 \mathrm{~min}$. $\mathrm{O}$ amplicon resultante foi checado em gel de agarose a $2 \%$, colocado em cuba de eletroforese durante um hora a 100V. A visualização foi efetuada através de luz ultravioleta (UV).

\section{PCR nested e TGR-PCR}

Todas as amostras negativas e controles foram submetidos a PCR nested. Para tanto, foi retirado $1 \mu$ l do produto de $\mathrm{PCR}$ simples e adicionado à mistura de reação [tampão $10 \mu \mathrm{l} \times 5 \mu \mathrm{l} ; \mathrm{MgCl}(50 \mathrm{mM}) 1,5 \mu \mathrm{l}$; primer ToxoN2 (50pmol/ $\mu \mathrm{l}) 1 \mu \mathrm{l}$; primer Toxo-C2 (50pmol/ $\mu \mathrm{l}) 1 \mu \mathrm{l}$; DNTPs $(10 \mathrm{mM}) 1 \mu \mathrm{l}$; Taq polimerase $0,5 \mu \mathrm{l}$; água Mili-Q q.s.p. $50 \mu$; óleo mineral $30 \mu l]$.

Repetiu-se o processo nas mesmas condições anteriormente citadas.

A metodologia de PCR simples foi repetida utilizandose o par de primers $\mathrm{ABGTg}$ C1 e N1 da seqüência do elemento repetitivo TGR, nas mesmas condições de reação, e posterior checagem do material.

\section{Imunoperoxidase}

O estudo imunoistoquímico foi realizado pelo método de avidina-biotina-peroxidase (ABP), utilizando-se anticorpo policlonal anti-T. gondii (Dako), pré-diluído, e, como revelador, a diaminobenzidina (DAB), marca Dako. As amostras foram previamente emblocadas e identificadas. Foram analisados tecidos placentários, representados por decídua, vilosidades córion e cordão umbilical. Foram realizados cortes histológicos de $3 \mu \mathrm{m}$ cada, colocados em lâminas previamente revestidas com silano (Sigma). Posteriormente, os cortes foram desparafinizados em estufa a $57^{\circ} \mathrm{C}$ e submetidos a banhos de imersão sucessivos em xilol, álcool e água corrente. Foi realizada a inibição da peroxidase endógena com solução de peróxido de hidrogênio e metanol durante $10 \mathrm{~min}$. Após, foi feita a incubação com anticorpo primário anti-T. gondii, por um período de 12 horas overnight, empregando-se o método de imunoperoxidase (ABP), com posterior revelação com $D A B$. Os cortes foram contracorados com hematoxilina de Mayer e montados com bálsamo sintético. Foram utilizados casos-controles positivos, previamente analisados e contendo elementos parasitários teciduais de T. gondii.

\section{Resultados}

A PCR apresenta elevada sensibilidade (de um a dez parasitas), especificidade de $100 \%$ com os DNAs testados, além de rapidez na liberação do resultado do teste. Como vários autores já relataram, maior sensibilidade $(92,9 \%)$ e total especificidade, com o resultado em 24 horas, são obtidas pela PCR, principalmente no diagnóstico da infecção fetal $(3,11,14)$.

No trabalho executado, para dar confiabilidade à metodologia implantada, foi testada a especificidade utilizando-se amostras de DNA de várias origens, não ocorrendo reações cruzadas (Figura 1).

Para testar a sensibilidade da PCR simples com os primers B1 foi utilizada curva de taquizoítas de T. gondii, observando-se o aparecimento de uma banda de 194pb, com dez taquizoítas; fazendo-se o nested, observou-se uma banda de $97 \mathrm{pb}$, com um taquizoíta (Figuras 2 e 3). Através da PCR simples, com dois pares de primers ABGTg, observou-se o aparecimento de uma banda específica de 145 pb com um taquizoíta (Figura 4).

Uma vez estabelecidas as condições ótimas de amplificação com os primers B1 e ABGTg, realizou-se o ensaio de PCR no DNA obtido das amostras dos pacientes, sendo que todas foram negativas no ensaio de amplificação.

\section{Discussão}

Apesar de a metodologia estar bem estabelecida e observando-se todos os resultados negativos das amostras, há a possibilidade da presença de resultados falsonegativos. Várias poderiam ser as causas disso: haver a presença de inibidores da Taq polimerase, o período entre a infecção e a coleta da amostra ser muito longo, a parasitemia ser fugaz e as pacientes terem iniciado seu tratamento antes de efetuar a coleta. Estes fatos, mais a 


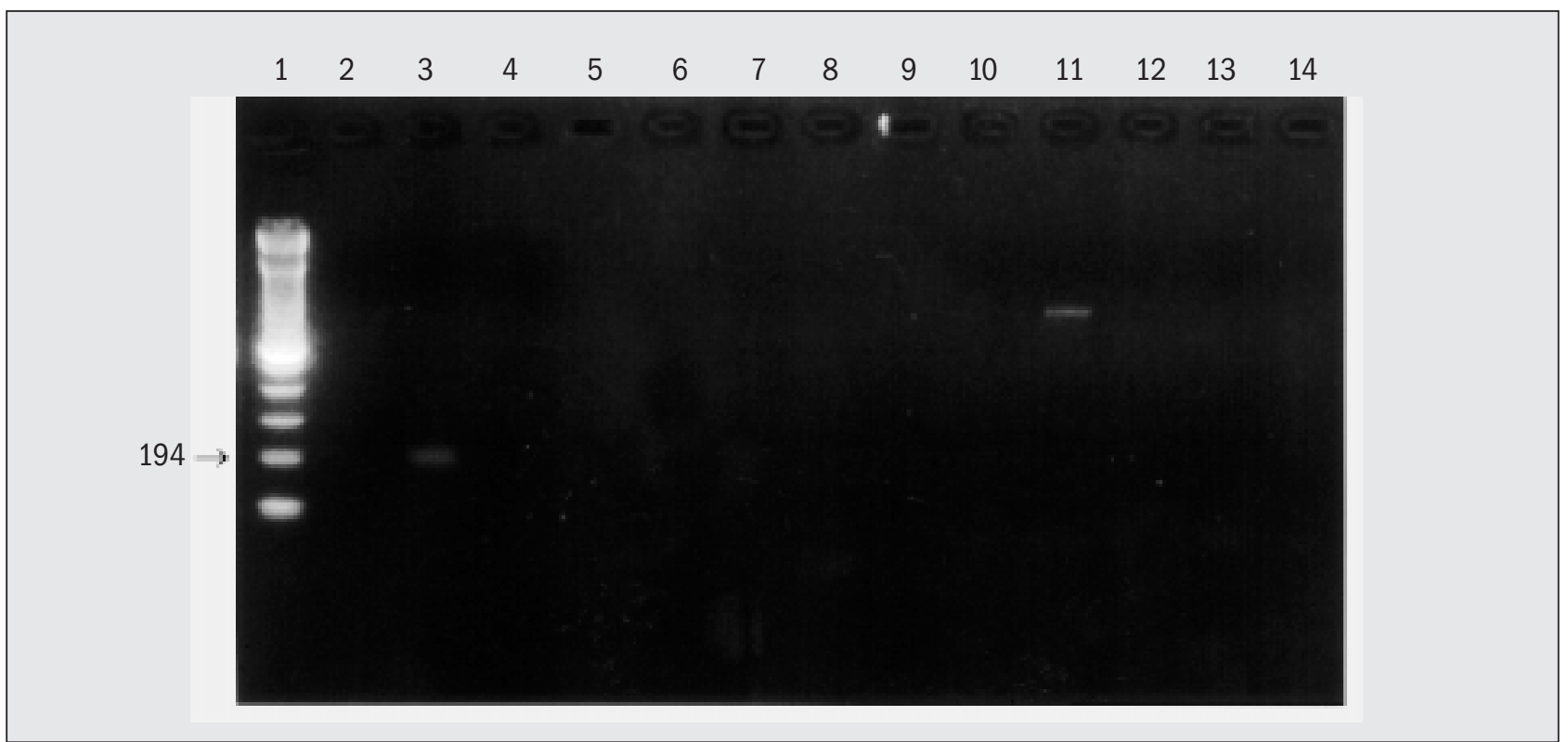

Figura 1 - Produtos de amplificação através de PCR simples com primer B1. Eletroforese em gel de agarose a 2\% com brometo de etídio. 1) Marcador de 100pb; 2) um taquizoíta

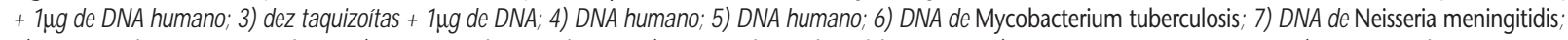
8) DNA de Echinococus granulosus; 9) DNA de Trichuris trichiura; 10) DNA de Plasmodium falciparum; 11) DNA de Trypanosoma cruzi; 12) DNA de Leishmania amazonensis; 13) DNA de Cryptosporidium spp.; 14) controle negativo de reação

sensibilidade, também poderiam explicar o isolamento parasitário negativo obtido pela inoculação em animais. É preciso observar que o tratamento poderia ser responsável por uma diminuição da infecção, em crianças, da ordem de $40 \%$ a $60 \%$. Desta forma, o diagnóstico negativo confirmaria a eficiência do tratamento preventivo da pirimetamina e sulfadiazina na replicação parasitária no

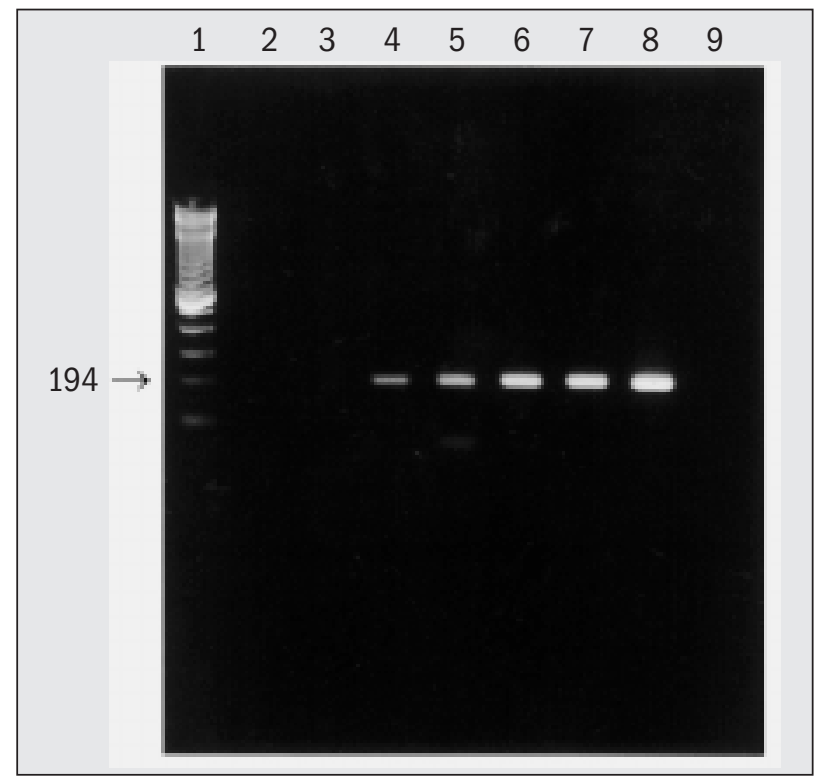

Figura 2 - Produtos de amplificação através de PCR simples com primer B1, curva de parasitas para avaliação da sensibilidade. Eletroforese em gel de agarose a 2\% com brometo de etídio. 1) Marcador de 100pb; 2) controle negativo de reação; 3) um taquizoíta de T. gondii; 4) dez taquizoítas; 5) cem taquizoítas; 6) $10^{3}$ taquizoítas; 7) $10^{4}$ taquizoítas; 8) $10^{5}$ taquizoítas; 9) controle negativo de extração útero. Deve-se salientar também que, nas avaliações dos resultados pela PCR das placentas, a espiramicina age reduzindo a carga parasitária neste local $(2,17,20)$. Como o tratamento pode induzir a liberação do DNA do parasita, a PCR pode manter-se positiva por alguns dias (quatro a, no máximo, 12 dias) após o início da terapia (5). Diante do exposto, sugere-se que as coletas sejam feitas antes do início do tratamento, o que, por razões éticas, não foi possível executar neste trabalho.

Por razões práticas, é impossível a avaliação de toda a placenta, e a extração do DNA de tecidos é mais difícil que de líquidos. Porém, mesmo que a placenta seja um material biológico de fácil obtenção, ela não é o mais indicado para a identificação do genoma parasitário pela baixa sensibilidade $(8,9)$.

A PCR de amostras de sangue é mais sensível que a inoculação em camundongos. Quando se faz uso de inoculação, junto com as células utilizadas podem estar presentes fatores inibitórios. Da mesma forma, frações do genoma do parasita são identificadas por PCR, porém não são viáveis para a proliferação em camundongos $(5,13)$.

A obtenção de sangue em gestantes é um método menos invasivo e não requer um especialista, porém apresenta baixa sensibilidade (1). A PCR em líquido amniótico apresenta alta sensibilidade e confirma que o parasita está invadindo o feto, porém sua obtenção requer um especialista e, como qualquer técnica invasiva, apresenta riscos à gestação. 


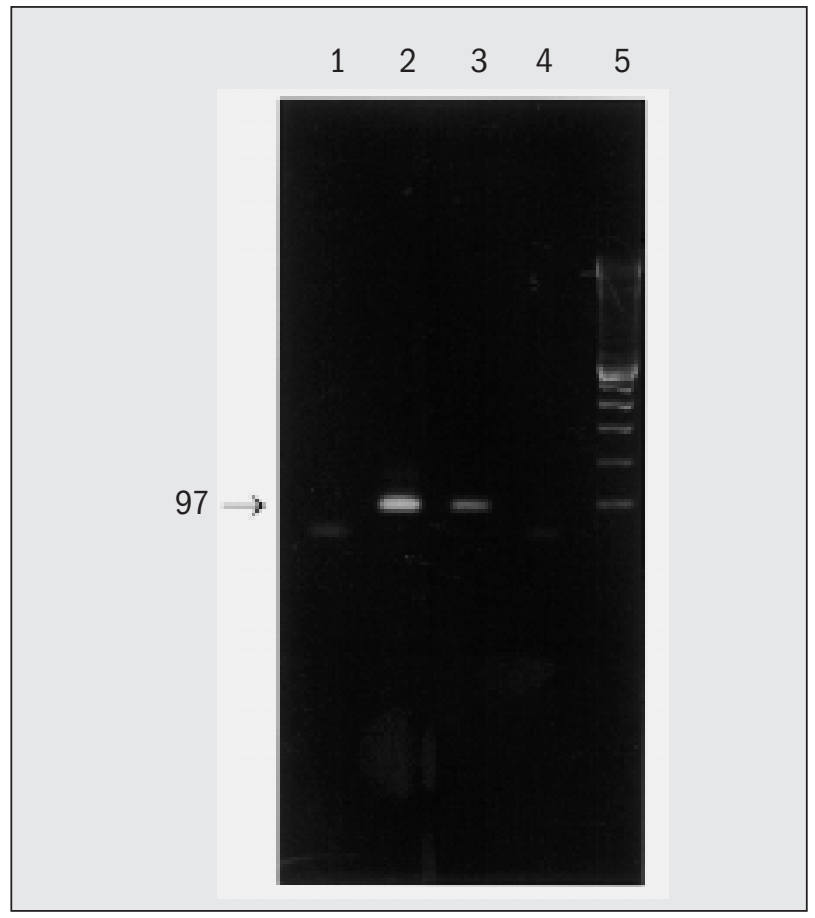

Figura 3 - Produtos de amplificação através de PCR nested com primer B1. Eletroforese em gel de agarose a $2 \%$ com brometo de etídio. 1) Controle negativo de extração; 2) dez taquizoítas de T. gondii; 3) um taquizoíta; 4) controle negativo de reação; 5) marcador de 100pb

Em trabalho executado por Guy \& Johnson (12) para identificação de infecção ativa por T. gondii no sangue periférico utilizando PCR nested, foram obtidos resultados negativos em pacientes com infecção crônica, o que recomenda o uso deste material para o diagnóstico de infecção aguda e sugere que a detecção de DNA parasitário pode ser rara no sangue periférico durante a fase crônica da infecção. É importante salientar, porém, que uma PCR negativa não exclui a infecção recente.

O diagnóstico da toxoplasmose é geralmente baseado em argumentos indiretos (sorológicos); todavia, em casos de imaturidade ou depressão imunológicas, a evidência do parasita deve ser obtida.

A reação de polimerase em cadeia mostrou-se sensível quando foram utilizados dois jogos de primers do gene $B 1$ e um novo jogo de primers da seqüência TGR (ABGTg C1 e N1), sendo específica com amostras de DNA humano e de diferentes agentes infecciosos com os quais não apresentou reação cruzada. Salientamos que os primers TGR foram mais sensíveis, portanto poderiam ser excelentes candidatos como alternativa à utilização dos primers B1. Desta forma, esta metodologia pode ser utilizada com segurança e confiabilidade, além de tornar rápido o diagnóstico da toxoplasmose congênita, servindo de ferramenta importante na avaliação pré-natal. Todavia é necessário que seja otimizada a coleta das amostras. Para tanto sugerimos que seja efetuada uma coleta de sangue com EDTA antes do início da terapêutica específica e, quando possível, em dois, quatro, oito e 12 dias do tratamento.

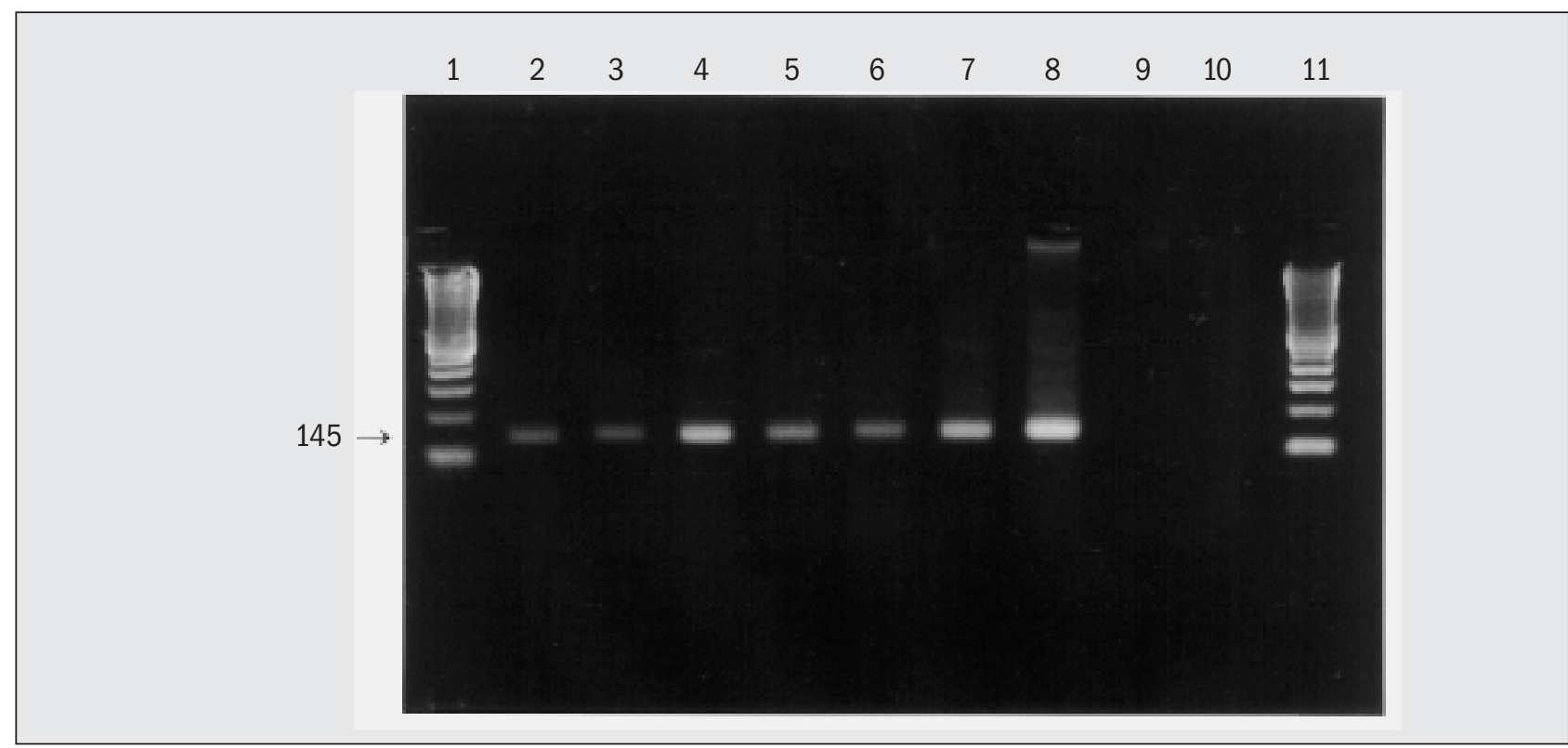

Figura 4 - Produtos de amplificação através de PCR com primer $\mathrm{ABGTg}^{7} \mathrm{Cl}$ e N1, curva de sensibilidade. Eletroforese em gel de agarose a 2\% com brometo de etídio. 1) Marcador de 100pb; 2) um taquizóta; 3) dez taquizóttas; 4) cem taquizoítas; 5) $10^{3}$ taquizoítas; 6) $10^{4}$ taquizoítas; 7) $10^{5}$ taquizoítas; 8) $10^{6}$ taquizoítas; 9) controle negativo de extração; 10) controle negativo de reação; 11) marcador de 100pb 


\section{Referências}

I. Angel, S.O. et al. Screening for active toxoplasmosis in human patients by DNA hybridizations with ABGTg7 probe in blood samples. J. Clin. Microbiol., 35: 591-5, 1997.

2. Beazley, D.M. \& Egerman, R.S. Toxoplasmosis. Semin. Perinato.,I 22(4): 332-8, 1998.

3. Camargo, M.E. Alguns aspectos atuais do diagnóstico de laboratório da toxoplasmose. Am.Acad. Nac. Med., 1 55(4): 2369, 1995

4. Cristina, N. et al. A family of repeated DNA sequences in Toxoplasma gondii: cloning, sequence analysis and use in strain characterization. Exp. Parasitol., 73: 73-8I, I991.

5. Dupouy-Camet, J. et al. Detection of Toxoplasma gondii in venous blood from AIDS patients by polymerase chain reaction.J. Clin. Microbio., I 31: 1866-9, 1993.

6. Forestier, F. et al. Prenatal diagnosis of congenital toxoplasmosis by PCR: extended experience. Prenat. Diagn., 18(4): 407-9, 1998.

7. Frenkel, J.K. Pathology and pathogenesis of congenital toxoplasmosis. Bull. NY Acad. Med., 50: I82-91, 1974.

8. Fricker-Hidalgo, H. et al. Detection of Toxoplasma gondii in 94 placentae from infected women by polymerase chain reaction, in vivo and in vitro cultures. Placenta, 19: 545-9, 1998.

9. Fricker-Hidalgo, $\mathrm{H}$. et al. Prenatal diagnosis of congenital toxoplasmosis: comparative value of fetal blood and amniotic fluid using serological techniques and cultures. Prenat. Diag., 17: 831-5, 1997.

10. Garcia, A. Aspectos morfológicos feto-placentários na infecção congênita pelo Toxoplasma gondii. Am. Acad. Nac. Med., 155: 229-3।, 1995.
II. Grover, C.M. et al. Rapid prenatal diagnosis of congenital Toxoplasma infection by using polymerase chain reaction and amniotic fluid. J. Clin. Microbiol., 28: 2297-30I, 1990.

12. Guy, E.C. \& Joynson, H.M. Potential of the polymerase chain reaction in the diagnosis of active Toxoplasma infection by detection of parasite in blood.J. Infect. Dis., 172: 319-22, 1995.

13. Hitt, J.A. \& Felice, G.A. Detection of Toxoplasma gondii parasitemia by gene amplification, cell culture, and mouse inoculation. J. Clin. Microbiol., 30: 3 I8I-4, 1992.

14. Hohlfeld, P. Prenatal diagnosis of congenital toxoplasmosis with a polymerase chain reaction test on amniotic fluid. N. Engl. J. Med., 33 1: 695-9, 1994.

15. Ho-Yen, D.O. et al. Use of the polymerase chain reaction to detect Toxoplasma gondii in human blood samples. J. Clin. Pathology, 45: $910-3,1992$.

16. Jacobs, L. Toxoplasma and toxoplasmosis. Ann. Rev. Microbiol., 17: 429-50, 1963.

17. Lynfield, R.; Hsu, H.W. \& Guerina, N.G. Screening methods for congenital Toxoplasma and risk of disease. Lancet, 353: I 899 900, 1999.

18. Matrajt, M. et al. Arrays of repetitive DNA elements in the largest chromosomes of Toxoplasma gondii. Genome, 42: 265-9, 1999.

19. McCabe, R.E. \& Remington, J.S. Toxoplasmosis: the time has come. The N. England. J. Med., 3/8(5): 313-5, 1988.

20. Robert-Gangneux, F. et al.Value of prenatal diagnosis and early postnatal diagnosis of congenital toxoplasmosis: retrospective study of 110 cases. J. Clin. Microb., 37(9): 2893-8, 1999.

21. Wong, S.Y. \& Remington, J.S. Toxoplasmosis in pregnancy. Clin. Infect. Dis., 18: 853-62, 1994. 